\title{
A retórica de aniquilação: reflexões acerca da campanha contra o Espiritismo no Brasil entre 1890 e 1940
}

\section{The rhetoric of nihilation: reflections upon the campaign against Spritism in Brazil between 1890 and 1940}

Frank Usarski*

Resumo: A estratégica retórica de "aniquilação" é um meio decisivo para manifestar intolerância religiosa. Segundo Peter L. Berger e Thomas Luckmann, trata-se da tentativa de uma entidade que atribui, em nome da maioria social, um status inferior a uma minoria religiosa. A eficácia dessa técnica depende da capacidade de um agente social de influenciar a imagem pública do fenômeno em questão e de sugerir que a campanha expressa um interesse comum. O sucesso desse processo de construçáo social da realidade, portanto, deriva de um talento duplo do "construtor". A primeira faculdade reside na redução da complexidade do respectivo fenômeno a seus supostos elementos cruciais. A segunda aptidão tem a ver com a associaçáo desses elementos a definições negativas pré-estabelecidas para que o "inimigo" apareça como uma mera variação de um fenômeno social já conhecido pela maioria como algo inaceitável. Com o intuito de demonstrar como e por que a estratégica de aniquilação funciona, a presente artigo se refere à campanha de autoridades brasileiras contra o Kardecismo entre 1890 e 1940.

Palavras-chave: Aniquilação retórica; intolerância religiosa; Kardecismo; Brasil.

Abstract: The rhetorical strategy of "nihilation" is a decisive means for manifesting religious intolerance. According to Peter L. Berger and Thomas Luckmann it is the attempt of an instance, which represents the social majority to attribute an inferior status to a religious minority. To be effective, the technique requires the capacity of a social actor of influencing the public image of the phenomenon in question in a way that a public interest in the campaign becomes obvious. The success of this process of social construction of reality depends on a twofold linguistic talent of the "constructor". The first faculty is to reduce the complexity of the challenging phenomenon to asserted "core elements". The second one is to associate these "core elements" to pre-established negative definitions so that the "enemy" appears as a mere variant of a well-known inacceptable social phenomenon. In order to illustrate how and why the strategy of nihilation works, this article refers to the campaign against Kardecism driven by Brazilian authorities between 1890 and 1940 .

Keywords: Rethoric nihilation; religious intolerance; Kardecism; Brazil.

* Professor livre-docente do Programa de Pós-Graduação em Ciência da Religião, da Faculdade de Ciências Sociais da PUC-SP. usarski@pucsp.br 


\title{
Introduçáo
}

Disputas entre diferentes comunidades de fé, bem como entre instâncias sociais seculares e comunidades religiosas, representam uma constituinte histórica. Um estudo dessas constelaçóes conflituosas revela a frequente presença de uma figura argumentativa caracterizada por Peter L. Berger e Thomas Luckmann como aniquilação. Trata-se de um instrumento retórico usado por um grupo desafiado pela presença de representantes de uma cosmovisão alternativa. O objetivo de uma argumentação aniquiladora é a desvalorização do "outro" em defesa da ideologia maioritária. Segundo os dois autores, "o aparecimento de um outro possível universo simbólico representa uma ameaça porque sua simples existência demonstra empiricamente que nosso próprio não é inevitável" (Berger; Luckmann, 1998, p. 147). Nessa situação, os defensores das convicçóes habituadas podem considerar adequado degradar o competidor por meio da construção retórica de um desnível qualitativo. Em outras palavras:

\begin{abstract}
A ameaça às definiçóes sociais da realidade é neutralizada atribuindo-se um status ontológico inferior, e com isso um status cognoscitivo que não deve ser levado a sério, a todas as definiçôes existentes fora do universo simbólico. (Berger; Luckmann, 1998, p. 155)
\end{abstract}

A classificação pejorativa de grupos concorrentes como pagãos ou seitas e a desvalorização de ensinamentos como heresia representam medidas bem conhecidas em prol da desvalorização do outro. Nem sempre a situação é tão óbvia. Há momentos em que o incômodo com uma religião alternativa náo se restringe a correntes religiosas predominantes, mas atinge também agências da sociedade geral. Além disso, é uma característica da estratégica da aniquilação a de disfarçar os verdadeiros interesses do discurso degradante.

Este ensaio pretende levar o conceito da aniquilação um passo adiante. As perguntas que norteiam o raciocínio elaborado a seguir é: como a figura argumentativa enfocada é construída? De quais mecanismos retóricos os aniquiladores se apropriam para garantir que uma campanha contra um adversário ideológico seja bem sucedida? Questóes semelhantes já foram objeto de uma reflexão em um outro contexto. $\mathrm{O}$ maior diferencial entre o texto apresentado aqui e seu antecessor encontra-se na parte da exemplificação. A publicação anterior torna plausíveis suas hipóteses por meio de casos relacionados a dois conflitos ideológicos sintomáticos da 
situação na Alemanha, isto é: primeiro, a briga entre a Igreja Luterana e o Budismo por volta da virada do século XIX para o século XX; seguido, a estigmatizaçáo coletiva de novos movimentos religiosos a partir da primeira metade da década de 1970. O presente artigo sustenta sua argumentação conceitual por referências à campanha contra o Espiritismo entre 1890 e 1940 no Brasil. Uma segunda diferença entre as duas publicaçóes reside na originalidade do material referencial. Enquanto os detalhes sobre os dois casos na Alemanha são fruto de pesquisas próprias, os dados sobre os esforços aniquiladores direcionados ao Espiritismo são oriundos de pesquisas de terceiros. $\mathrm{O}$ raciocínio aqui retomado, portanto, tem o caráter de uma análise secundária de dados amplamente conhecidos entre pesquisadores brasileiros interessados em assuntos afins, o que não invalida a pretensão de que a exploração do estado da arte em questão à luz do conceito da retórica de "aniquilação" revela facetas do tema ainda não suficientemente sistematizadas. Em função disso, o seguinte texto é organizado em três passos principais.

A primeira tarefa é a operacionalização do teorema norteador em termos de uma caracterização dos elementos constitutivos da retórica de aniquilação. Alusões a um dos casos de aniquilação na Alemanha elaborados no texto anterior ajudam a entender o conceito e evitam que o último fique preso ao nível abstrato.

$\mathrm{Na}$ segunda parte, será apresentado o resumo das reaçóes pejorativas ao Espiritismo logo depois da sua importação ao Brasil. O período enfocado abrange os anos entre 1890 e 1940. A delimitaçáo cronológica reflete mudanças cruciais no decorrer do debate sobre o Espiritismo. Até a última década do século XIX, as reações negativas ao Kardecismo foram sobretudo formuladas por porta-vozes da Igreja Católica. Por volta de 1890, o cenário mudou, dando espaço a adversários "seculares" que se apropriavam de argumentos não religiosos sustentados por uma legislação que identificava determinadas práticas espíritas como ilegais. Por dois motivos, o ano de 1940 pode ser considerado um divisor de águas na discussão sobre o Espiritismo. Primeiro, o Código Penal Brasileiro, reformulado em 07 de dezembro de 1940, evita qualquer alusão explícita ao Espiritismo; segundo, no questionário do censo nacional do mesmo ano o Espiritismo aparece pela primeira vez como categoria, o que sinaliza a aceitaçáo coletiva desta corrente como um dos segmentos lícitos do campo religioso brasileiro.

A parte final do presente texto oferece uma interpretação dos dados anteriormente sintetizados à luz do conceito de aniquilação retórica, bem como algumas conclusôes relevantes para a discussão sobre a intolerância religiosa em geral. 


\section{Elucidaçáo do conceito da retórica de aniquilação}

As reflexóes mais adiante partem da hipótese de que o processo de aniquilação implica duas estratégias retóricas intimamente inter-relacionadas. $\mathrm{O}$ primeiro princípio se constitui dos esforços de instâncias aniquiladoras para cunhar uma imagem pública do "concorrente" em que prevalecem aspectos negativos do fenômeno em questão. Isso significa que as informaçôes seletivamente ventiladas não pretendem replicar a verdadeira complexidade do adversário, mas, sim, chamar atenção particular para pontos que aumentam a probabilidade de que a campanha da estigmatização gere o efeito intencionado. Além do exagero seletivo de certos elementos do "desafiador", os "aniquiladores" apropriam-se da técnica da transferência de definiçôes negativas socialmente pré-estabelecidas à imagem simplificada do adversário. Sob essa condição, o concorrente aparece como mais uma variação de um fenômeno já conhecido como "perigoso", "duvidoso" ou "problemático" pela maioria social.

Os teólogos protestantes e, em escala menor, católicos, na Alemanha que, por volta da virada do século XIX para o século XX, posicionaram-se contra o Budismo recém-chegado ao país, tentaram a relacionar a religiāo asiática a preocupações "do fundo", como a crise do Ocidente que inquietava boa parte da população alemã da época. Entre 1880 e 1930, o país passou por um período perturbado (Peukert, 1988). Era uma época de acelerado progresso na área da tecnologia, que transformou uma sociedade agrícola em uma sociedade industrial. Essas mudanças geraram inúmeras contradiçóes no sentido de uma diversidade desconcertante de tendências, de uma heterogeneidade de atitudes e valores e de uma forte tensão entre tradicionalismo e modernização. Essa ambivalência, penetrando todas as áreas da vida, era percebida individualmente como uma insegurança emocional e uma desorientação cognitiva. Como reação a essas circunstâncias, desenvolveu-se, entre intelectuais daquela época, uma intensiva discussão sobre o conceito de "cultura" resultante da busca por uma ideologia "harmonizadora" e integrativa diante das forças centrífugas de uma sociedade altamente dinâmica. Todavia, nem todas as reflexôes sobre a cultura despertaram esperança no seio da ambiguidades e tensóes sociais. Pelo contrário. Houve autores que alertaram para a possibilidade de que as rápidas transformaçôes da sociedade de entáo pudessem minar até mesmo os fundamentos da civilização europeia. Uma das expressóes mais salientes desse tipo é o famoso livro de dois volumes de Oswald Sprengler, com o significativo título "O declínio do Ocidente" (Spengler, 1918-1920). Já algumas décadas antes dessa publicação, o termo fin de siècle tinha se estabelecido como uma designação do espírito da época 
entre 1870 e 1900. A noção referia-se etimologicamente à palavra latina finis saeculi, isto é, o fim do mundo, trazendo, pois, um significado ainda mais dramático do que o título sugestivo do livro de Sprengler. Embora no cotidiano geralmente não seja aproveitado nesse sentido radical, uma das possíveis leituras de fin de siècle era "decadência", um termo também em voga por volta da passagem do século XIX para o século XX (Brockhaus Enzyklopädie, 1988, p. 208).

Abstraindo aspectos admiráveis do Budismo, como sua profundidade filosófica, sua disciplina monástica, seu o rigor ético e sua postura tolerante diante de potenciais oponentes, as publicaçóes de porta-vozes, sobretudo da Igreja Luterana, mas também da Igreja Católica, concentraram-se na soteriologia budista e identificaram nela uma tendência de "fuga do mundo". O resultado foi a tristonha imagem de uma religião que se esgota na aspiração a um Nirvana incompatível com as orientações e os objetivos da cultura ocidental. Reforçando esse imaginário exagerado, autores cristãos envolvidos no "debate" destacaram o lado "mórbido" do Budismo. De acordo com essa percepção pejorativa, o conselheiro superior da Igreja Luterana, Ernst Haack, constatou:

A cultura de povos afiliados ao Budismo não dispóe de nenhuma força de progresso. Já desde séculos ela é condenada à estagnação e seria muito mais, se tivesse implantado consequentemente aquela apática filosofia do Nirvana de tédio de vida e da indiferença diante das questóes humanas. (Haack, 1898, p. 23)

No mesmo ano, o professor catedrático de Apologia da faculdade de Teologia Católica da Universidade de Bonn, Winfried Philipp Englert, recorreu à metáfora da "toxina oriental da interiormente já morta cultura budista" (Englert, 1898, p. 11) e afirmou que os povos asiáticos estariam no "alcance da sombra da morte nas trevas do Budismo" (Englert, 1898, p. 18). Quatro anos mais tarde, o superintendente luterano Robert Falke acrescentou, a respeito do monaquismo budista: "Cansado, apático e preguiçoso, o discípulo fiel de Buda arrasta-se através da vida e da ânsia pelo silêncio da morte" (Falke, 1902, p. 73).

Essas citações apontam para os dois componentes constitutivos da retórica da aniquilação. Apesar de o Budismo representar uma afronta religiosa para os representantes das duas principais igrejas alemãs, os teólogos cristáos raramente fizeram uso de argumentos apologéticos no sentido estrito nas suas publicaçóes contra aquela religiáo. Em vez disso, abstraíram a complexidade da religiáo desafiadora, destacaram apenas determinados aspectos do sistema antagonista e supuseram que os elementos selecionados fossem manifestações típicas do "perigo 
amarelo", ou seja, de uma das forças que estavam ameaçando a integridade e vitalidade da cultura ocidental. A imagem pejorativa dessa religiáo, portanto, era fruto de uma transferência, atualização ou aplicação secundária de interpretaçáo negativas já existentes e enraizadas na consciência coletiva de camadas influentes do povo alemáo. Tudo isso significa que a campanha de autores cristáos contra o Budismo exemplifica as duas estratégicas típicas da retórica de aniquilação.

Como será demonstrado mais adiante, os mesmos princípios (a imagem simplificada do adversário e a transferência de definiçôes negativas socialmente pré-estabelecidas) caracterizaram o debate público sobre o Espiritismo brasileiro entre 1890 e 1940. Antes de abordar essa fase em particular, o leitor será lembrado de alguns dados referente à origem e às características gerais do Kardecismo, bem como ao processo da implantaçáo desta corrente religiosa no Brasil.

\section{Origem e características gerais do Kardecismo}

Em 8 de abril de 1857, em Paris, foi lançado "Le Livre des Esprits" ("O Livro dos Espíritos”), do francês Allan Kardec (1804 - 1869). Em 1814, Kardec tinha estudado com o pedagogo inovador Johann Heinrich Pestalozzi (1746-1827) em Zurique. Até a publicação do "Livro dos Espíritos", Kardec, ainda sob seu verdadeiro nome - Hyppolyte Leon Denizard Rivail -, tinha escrito algumas obras pedagógicas em que defendia abordagens discutidas em círculos acadêmicos da época, dentre elas a ideia da evoluçáo da humanidade em etapas, a epistemológica positivista e a ética altruísta.

Do ponto de vista da História da Religião, é relevante que "Le Livre des Esprits" tenha sido publicado nove anos após o surgimento dos primeiros boatos sobre espíritos que se tinham manifestado por batidas na casa das irmãs Katherine Fox (1837-1892), Leah Fox (1814-1890) e Margret Fox (1833-1893), em Hydesville, no Estado de Nova Iorque. Nesse sentido, "O Livro de Espíritos" foi uma das manifestaçôes da "febre das sessóes espiritas" (LINSE, 1996: 55) que grassou pela Europa da segunda metade do século XIX.

Segundo Kardec, a publicação era o resultado de observaçôes empíricas feitas no âmbito de reunióes de que tinham participado médiuns espirituais (KARDEC, 1995: 204ss). No prefácio, o autor reivindica que o sistema apresentado por ele na obra basear-se-ia em estudos sobre seres fenômenos visíveis intermediados por seres humanos com faculdades mediúnicas, bem como a reflexão filosófica, científica e religiosa sobre os respectivos acontecimentos. Na sua essência, porém, 
[...] o Espiritismo é a ciência nova que vem revelar aos homens, por meio de provas irrecusáveis, a existência e a natureza do mundo espiritual e as suas relaçóes com o mundo corpóreo. Ele no-lo mostra, não mais como coisa sobrenatural, porém, ao contrário, como uma das forças vivas e sem cessar atuantes da Natureza, como a fonte de uma imensidade de fenômenos até hoje incompreendidos e, por isso, relegados para o domínio do fantástico e do maravilhoso (Kardec, 2013, p. 44).

Kardec acreditava em um Deus criador unitário. Simultaneamente, postulava a lei do karma junto com a ideia de evolução continua da alma através das suas reencarnaçóes. Nesse sentido, a vida atual seria consequência da qualidade moral das existências anteriores e as constelaçóes encontradas pelo indivíduo no decorrer do seu longo caminho ofereceriam liçóes que promovem o futuro progresso. Princípios cruciais, nesse sentido, são a aquisição de conhecimento sobre as estruturas do universo e as regras universais que o sustentam, a responsabilidade pessoal do ser humano para com suas açóes e a força normativa da ética altruísta. Para Kardec, Cristo era uma personalidade altamente evoluída do ponto de vista ético, cujo comportamento deve servir como modelo universal de conduta no espírito de amor pelo próximo e caridade. Em termos antropológicos, o sistema de Kardec assume que o ser humano, na sua manifestação biográfica, é composto por três componentes. Além da alma imortal e do corpo perecível há uma instância intermediadora entre ambos, isto é, o corpo astral. As fronteiras entre o mundo físico e o além são difusas. Ambas as esferas existem paralelamente, o que permite comunicaçóes entre almas encarnadas e não encarnadas por meio de médiuns sensíveis para esta realidade estendida. Segundo Kardec, todos os seres humanos possuem um determinado grau de capacidades mediúnicas (Kardec, 2004, p. 147ss). O termo “médium” em sentido estrito, porém, refere-se apenas àquelas pessoas que têm desenvolvido tais faculdades de maneira extraordinária e "óbvia”. Esses dons se manifestam em seus "portadores" de maneiras variadas. Além de seres humanos que têm o talento de vidência ou recebem as mensagens do além pela via auditiva, há médiuns de diferentes subcategorias equipados com a faculdade de curar. Alguns curam pelo contato visual, mediante o contato corporal ou através de determinados gestos. Outros recebem instruçóes de médicos falecidos e prescrevem receitas de acordo com as informaçóes adquiridas desta maneira.

\section{A recepçáo do Kardecismo e a evoluçáo do espectro espiritista no Brasil}

A partir de 1853, circulavam no Brasil notícias sobre o fenômeno das chamadas "mesas girantes", supostamente observado nos EUA e na Europa de então. Esses 
comunicados foram divulgados pela mídia no Rio de Janeiro e Recife. Mais importante foi o fato de que, a partir de 1860 circulavam, inicialmente entre pequenos grupos esotéricos e apenas em língua francesa, as fontes impressas do Kardecismo. A situaçáo mudou consideravelmente com o surgimento das obras de Kardec traduzidas para o português. As primeiras foram $O$ livro dos Espiritos, $O$ livro dos Médiuns e $O$ Céu e o Inferno, lançadas em 1875 pela Livraria Garnier, na época a editora mais importante no Rio de Janeiro. Logo depois, autores brasileiros, baseados nas obras originais de Kardec, começaram a publicar contribuiçôes próprias para o desenvolvimento do Espiritismo no País. Além disso, periódicos como O Echo d'Álem-Túmulo, (a partir de 1869) ou a Revista Espirita (a partir de 1875) ofereceram oportunidades para o avanço e a divulgação das ideias espíritas. Nessas publicações manifestaram-se diferenças conceituais que se explicam pelas preferências e divergentes interpretaçóes dos autores envolvidos. Algo semelhante vale para os grupos espíritas e suas ramificaçôes que surgiram a partir da década de 1860 em diferentes regiôes do Brasil, entre eles a primeira associação local, o Grupo Familiar do Espiritismo fundado em 1865 pelo jornalista Luís Olímpio Teles de Menezes (1828-1893) em Salvador, do qual se separou a Associação Espírita Brasileira em 1873 e da qual, por sua vez, se emancipou o Grupo Santa Teresa de Jesus, em 1874.

Com o tempo, essa dinâmica deu luz a um campo altamente heterogêneo de grupos com perfis próprios em termos de nomenclatura, conceitos e órgáos de publicação. Por volta de 1900, já havia 19 revistas espiritistas no País. (Stoll, 2005, p. 50) A variedade de associaçóes e veículos de publicação coexistentes na época indica que a expressão "espiritismo" servia mais como um vago termo genérico do que como noção precisa de um ramo religioso internamente consistente. (Giumbelli, 1997, p. 31) Em vez disso, a designação representava uma série de fenômenos interrelacionados pela fé comum dos seus portadores na presença de seres espirituais e suas intervençóes no cotidiano dos vivos. Além desse consenso mínimo, cada grupo demonstrava preferências próprias de acordo com o caráter polissêmico do "espiritismo" no sentido de elementos científicos, filosóficos e religiosos. Sob essas condiçóes, atuavam grupos que destacavam o estudo coletivo dos livros do Kardec, ao lado de círculos cujos integrantes demonstraram um interesse mais amplo, incluindo nas suas leituras as obras de outros autores "esotéricos", como as de JeanBaptiste Roustaing (1805-1879), Emanuel Swedenborg (1688-1722) ou Helena Blavatsky (1831-1891). Diferenças semelhantes existiam entre os espíritas "científicos", que destacaram o caráter empírico dos fenômenos estudados por eles, e aqueles que entenderam a doutrina do "mundo paralelo" como um desafio 
filosófico. Paralelamente, havia abordagens de chamados espíritas "ocultistas", especialmente interessados nas manifestações de espíritos e seus impactos no mundo físico, bem como de espíritas "religiosos", comprometidos com a criação de pontes entre os ensinamentos de Kardec e o Catolicismo (Arribas, 2008, p. 72-73).

A heterogeneidade do campo se mostrou também em relação à presença de médiuns de cura nas diferentes instituições. Caso um grupo se engajasse no sentido terapêutico, fazia isso em um contexto legitimador que emprestava seus argumentos da homeopatia que estava se espalhando pelo país - e, em diversos momentos, imediatamente relacionado ao Kardecismo -, a partir da década de 1840. Um personagem importante nesse sentido foi o médico francês Benoît Jules Mure (1809-1858), que tinha estudado a abordagem de Samuel Hahnemann (1755-1843), "mentor" da homeopatia na Europa. O projeto principal de Mure no Brasil era a fundação da comunidade experimental Falanstério do Saí, na península de Saí, em Santa Catarina, que seguia a abordagem do socialista francês François Marie Charles Fourier (1772-1837) e em cujo meio Benoît Jules Mure inaugurou um instituto homeopático. Em consequência do fracasso do projeto, Mure mudou-se em 1843 para Rio de Janeiro, onde fundou o Instituto Hahnemanniano do Brasil. Permaneceu presidente do Instituto até 1848, ano do seu retorno à Europa. Nesse ínterim, Benoît Jules Mure estabeleceu no Rio de Janeiro, junto com o cirurgião João Vicente Martins (1808-1854), que tinha imigrado de Portugal para o Brasil, 26 ambulatórios locais, nos quais sobretudo escravos e pobres eram tratados com métodos homeopáticos (Sigolo, 1999, p. 46-47).

A partir de 1860, intensificou-se a influência do Espiritismo sobre o universo homeopata no Brasil. Simultaneamente, centros espíritas tornaram-se catalisadores da divulgação mais ampla da homeopatia. Um elemento doutrinário crucial nesse contexto era a associação da "força vital”, segundo Samuel Hahnemann responsável pela defesa imunológica, ao ensinamento de Kardec sobre o "corpo astral” e seus graus de pureza vinculados à saúde humana.

\section{As críticas ao Espiritismo entre 1890 e 1940}

No decorrer da segunda metade do século XIX, os grupos espíritas no Brasil e as doutrinas e práticas promovidas por eles tornaram-se alvos de críticas cada vez mais intensas. Do ponto de vista cronológico, os anos entre 1890 e 1940 marcaram uma segunda fase da resistência ao Espiritismo. As preocupaçôes antes desse período foram articuladas por representantes da Igreja Católica. Os argumentos tinham um 
caráter religioso propriamente dito. Os teólogos salientavam elementos doutrinários e práticas em desacordo com a fé cristá, especificamente aspectos como a reencarnação, a possibilidade de o ser humano aperfeiçoar-se no decorrer da sua evolução individual, o conceito de "mundo paralelo" ou as tentativas de contato de pessoas vivas com pessoas falecidas.

Além disso, uma reclamação era de que o Espiritismo rejeitava o conceito de pecado original. Dessa maneira, "sustentando que o inferno e o paraíso são apenas figuras, professando a reencarnaçáo e a purificação contínua, roubando-nos a perspectiva de uma vida futura que o catolicismo nos abre nas bordas do túmulo" (Moreira, 1863, p. 8). Por essa razáo, a doutrina do Espiritismo seria náo apenas irracional, mas "altamente irreligiosa" (idem).

Essas críticas iniciais, porém, não tiveram grande impacto sobre o público brasileiro. Tal relativa insignificância política teve a ver, sobretudo, com o fato de que, com base na Constituiçáo de 1824, o governo brasileiro era comprometido com o princípio da tolerância religiosa, no qual já repercutia a formulação decisiva da ideia da neutralidade do Estado pela Constituição republicana de 1891.

A partir de 1890, o teor da crítica mudou a favor de argumentos "profanos". Com essa virada, abriu-se para os críticos ao Espiritismo um novo terreno discursivo isento da suspeita de que os ataques aos seguidores de Kardec poderiam minar a liberdade religiosa constitucionalmente garantida. No primeiro momento, os alertas sobre o Espiritismo circulavam ao redor da acusaçáo de curandeirismo e charlatanismo. Mais tarde, foi adicionado um terceiro elemento da crítica, a saber: a preocupação com a psico-higiene e a suspeita que o Espiritismo era uma fonte potencial de doenças mentais. Correspondentemente, os antagonistas mais fervorosos não se encontravam mais entre teólogos norteados por motivos religiosos, mas, sim, entre médicos orientados por interesses sociais e profissionais.

\section{Quais foram as condiçóes sócio históricas responsáveis por estas mudanças?}

Até o início do século XIX, médicos e cirurgiōes de diferentes níveis de formação agiam no Brasil ao lado de autodeclarados curandeiros que se apropriavam de abordagens terapêuticas de diferentes etnias, inclusive as de tribos indígenas, e de práticas populares de origem europeia. Enquanto a população não se mostrava muito seletiva diante dos procedimentos curativos acessíveis, os representantes do conhecimento medicinal europeu reivindicavam um monopólio do controle sobre os meios de tratamento do corpo humano. Especialmente os médicos formados em 
Coimbra, apoiados pela Igreja Católica e pela corte portuguesa, assumiram a tarefa de delimitar seus procedimentos terapêuticos de métodos baseados em "superstição". (Edler, 2006)

A ascensão da medicina científica no início do século XIX foi forçada por dois fatores. Primeiro, a transferência do corte portuguesa ao Brasil e seu estabelecimento definitivo no Rio de Janeiro em 8 de março de 1808 foi acompanhada por um impulso de inovação que se manifestava, entre outros indícios, na fundação de uma série de instituiçóes científicas. Segundo, epidemias de febre amarela (Ribeiro, 1992, p. 93) chamaram atenção para a significância e necessidade de profissionalização do setor da higiene e da saúde em nível nacional.

No início, as inovaçóes relacionadas à chegada do rei foram geograficamente limitadas. O primeiro beneficiário foi Salvador, então centro político do Brasil e paradeiro temporário da família real. Nessa cidade ocorreu, em 18 de fevereiro de 1808, a fundação da primeira entidade médica do País, isto é, a Escola de Cirurgia, seguida pela Escola Anatômica, Cirúrgica e Médica do Rio de Janeiro, em 05 de novembro do mesmo ano.

Em 1813, ambas as escolas foram renomeadas Academias Médico-Cirúrgicas. Em 1832, foram elevadas ao status de Faculdades de Medicina. Elas permaneceram as únicas entidades deste tipo no Brasil imperial. Outras foram fundadas apenas depois da Proclamação da República (15.11.1889).

Esse desenvolvimento institucional correspondeu à redefinição e expansão do domínio da competência da medicina. A saúde, até entáo focada no tratamento curativo de indivíduo, passou a se transformar em um empreendimento macrossocial. Mais do que isso: a medicina tinha a pretensão de se tornar uma espécie de guardiã da sociedade. Segundo um artigo na Gazeta Medica da Bahia publicado em 1899, caberia aos médicos da época “a orientação scientífica [sic], que assegura a execucção [sic] das boas leis e dá estabilidade e firmeza aos melhores planos de progresso e engrandescimento do paiz [sic]" (apud Schwarcz 1993, p. 202). Em outras palavras: "Com uma clara orientação programática da ciência médica para a 'redenção' do povo brasileiro, a figura do médico passou a competir com o 'homem de lei' - do jurista - sobre a missão do orientador e tutor dos destinos da nação" (Araújo, 2016, p. 41).

O poder simbólico implícito na atribuição da ampla competência ao setor da medicina foi comprovado na definição de doenças e em sua identificação em zonas de conflitos da sociedade humana. Essas delimitaçóes atingiram portadores de 
distúrbios mentais que, a partir de 1830, foram tratados pela medicina oficial como pacientes a serem isolados e controlados em instituiçóes apropriadas. Outros indicadores da influência da medicina são a relevância crescente da medicina legal de época e sua influência cada vez mais forte sobre os resultados de tribunais. (Machado, 1978, p. 193ss)

Além do privilégio de definição e identificação de doenças, os médicos reivindicavam o monopólio de tratar e curar. Essa demanda repercutiu na fundação da Sociedade da Medicina e Cirurgia do Rio de Janeiro (1829), que centralizou nacionalmente o controle medicinal que até entáo tinha sido de responsabilidade de administraçôes locais. Algo semelhante vale para as institucionalizaçóes da Junta Central de Higiene Pública (1850) e da Sociedade Farmacêutica Brasileira (1851), que tinham como tarefa de regulamentar e supervisionar o exercício da farmácia no país. (Dicionário Histórico-Biográfico das Ciências da Saúde no Brasil)

Paralelamente, os médicos proclamaram seu direito exclusivo de normatizar e certificar a formaçáo medicinal. As primeiras diretrizes desse tipo remontam a 1832, ano de concessão do status de Faculdade às duas entidades medicinais em Salvador e no Rio de Janeiro, exigindo dos médicos praticantes um diploma emitido ou por uma das duas faculdades supracitadas ou por uma instituição correspondente no Exterior. Por esse motivo, foram rejeitados em 1853, 1881 e 1900 os pedidos do Instituto Hahnemanniano do Brasil de estabelecer uma cadeira homeopática na Faculdade de Medicina de Rio de Janeiro (Sigolo, 1999, 252).

A mesma dinâmica era responsável pela formulação dos artigos 156, 157 e 158 do Código Penal da República, editado em 11 de outubro de 1890, que previram penas drásticas para quem cometesse atos ilegais na área de medicina, dentre eles "praticar a homeopatia, a desometria, o hipnotismo ou magnetismo animal, sem estar habilitado segundo as leis e regulamentos" (Art. 156), "praticar o espiritismo, a magia e seus sortilégios, usar de talismãs e cartomancias, para despertar sentimentos de ódio ou amor, inculcar cura de moléstias curáveis ou incuráveis, enfim, para fascinar e subjugar a credulidade pública" (Art. 157) ou "ministrar ou simplesmente prescrever, como meio curativo, para uso interno ou externo, e sob qualquer forma preparada, substância de qualquer dos reinos da natureza, fazendo ou exercendo assim, o ofício do denominado curandeirismo" (Art. 158).

A pretensão de proteger as abordagens oficiais diante de procedimentos ilegítimos de cura manifestou-se também em esforços de aplicar às ultimas rótulos pejorativos pré-estabelecidos, como charlatanismo e curandeirismo. 
Foi nesse clima que o Espiritismo se tornou o alvo predileto de agências brasileiras de controle medicinal. Seus funcionários abstraíram a diversidade interna do campo mirado e dirigiram sua mira apenas para doutrinas e atividades que cabiam nas categorias negativas supracitadas. De acordo com o ideal da "saúde pública", foi questionada, entre outros aspectos, a proposta de determinados representantes do Espiritismo de tratar problemas corporais e psicológicos através da imposição das mãos de terapeutas nos pacientes. Paralelamente, grupos de espíritas que tinham abertamente defendido a abordagem de Hahnemann começaram a pagar o preço pela simpatia em relação à homeopatia. A partir de 1891, houve casos em que espíritas foram presos sob a acusação de ter violado a proibição de aplicar procedimentos ilegais de cura em pacientes. Para evitar dificuldades dessa natureza, alguns centros espíritas tomaram a decisão de dissolver seus grupos. (Arribas, 2008, p. 92-93)

A recepção da discussáo entre especialistas europeus sobre temas como hipnose, sugestão e manipulação da mente resultou em uma ampliação do espectro de acusaçóes. As últimas não se contentavam com o argumento de que as "realidades paralelas" vivenciadas por médiuns espíritas durante as sessôes seriam projeçôes patológicas de indivíduos predestinados para doenças mentais. Traziam, também, a suspeita de que as reunióes nos centros espíritas poderiam ter o fim escuso de manipular visitantes comuns. Isso não seria apenas um problema da psico-higiene individual, mas representaria, por conta dos "efeitos anômicos" das sessóes nos centros, uma ameaça à ordem pública (Giumbelli, 1997).

Nas décadas seguintes, este último raciocínio se impôs sobre as acusaçóes de "curandeirismo" e da "charlatanearia". Nos anos 1920 e 1930, a maioria das queixas derivavam de psiquiatras e médicos peritos judiciais. Entre os protagonistas dessa linha argumentativa encontravam-se Leonídio Ribeiro e Murillo de Campos, ambos representantes acentuados do sistema medicinal oficial da época. No seu livro $O$ Espiritismo no Brasil: contribuição ao seu estudo clínico e médico-legal (Ribeiro; Campos, 1931), eles identificaram no meio dos espíritas uma síndrome que poderia ser denominada "mediunopathia" ou "mediunomania". (Giumbelli, 1997, p. 50). Essa doença poderia ser provocada por visitas frequentes de um centro espírita. Portanto, o Espiritismo seria um perigo social que exigia a intervenção do Estado. Semelhantemente, o psiquiatra Xavier de Oliveira afirmou, em sua obra - cujo título sintomático era "Espiritismo e loucura" -, que o Espiritismo serviria como "a cocaína dos debilitados nervosos [...] com que se envenenam, todos os dias, os débeis mentais, futuros hóspedes dos asilos de insanos". (Oliveira, 1931, p. 211) 


\section{Conclusão}

Três conclusōes relativamente óbvias podem ser tiradas das reflexóes acima.

Primeira, o combate contra o Kardecismo no Brasil serve como exemplo da aplicação da estratégia da "aniquilaçáo" no decorrer da história das religióes.

Segunda, como em casos análogos, a campanha baseou-se em dois elementos retóricos constitutivos do processo de "aniquilaçáa". Os "aniquiladores' criaram uma imagem unilateral do Espiritismo, o que é o primeiro pré-requisito para um processo de aniquilaçáo. Essa versão simplificada do Espiritismo, por sua vez, foi interpretada como a manifestação de um problema social mais grave, o que é a segunda técnica tipicamente com a intenção de aniquilar um "adversário ideológico".

Finalmente, vale o seguinte: em termos estatísticos, o Espiritismo é, hoje depois do Catolicismo e do Protestantismo - a terceira corrente religiosa mais relevante no Brasil. Isso indica que um processo de aniquilação é altamente dependente de circunstâncias históricas. Argumentos estigmatizantes cunhados de acordo com o "espírito do tempo" podem perder força quando as condiçóes sóciohistóricas mudam. Isso não significa, porém, que uma campanha contra um grupo religioso não possa ser revitalizada a qualquer momento. $\mathrm{Na}$ medida em que um movimento que tinha se tornado vítima de aniquilação supere a pressão e ganhe adeptos, porém, decresce a probabilidade de que agentes sociais interessados na opressão daquele grupo "remobilizem" sentimentos coletivos de oposição. Nesse sentido, é mais provável que, no Brasil, a inclinação da maioria à aniquilação coloque fenômenos religiosos mais recentes na mira. Há, atualmente, inúmeros novos grupos que poderiam se tornar facilmente alvos de aniquilação. É tarefa continua da Ciência da religiáo de acompanhar criticamente essas tendências.

\section{Referências bibliográficas}

ARRIBAS, Célia da Graça: Afinal, espiritismo é religiäo? A doutrina espirita na formação da diversidade religiosa brasileira, tese de doutorado em Sociologia, Sáo Paulo: Universidade de São Paulo, 2008.

BERGER, Peter L.; LUCKMANN, Thomas: A Construção Social da Realidade, Petrópolis: Vozes, 1998.

BROCKHAUS ENZYKLOPÄDIE, Mannheim: Brockhaus, 1988. 
Dicionário Histórico-Biográfico das Ciências da Saúde no Brasil (1832-1930). Casa de Oswaldo Cruz, Fiocruz, http://www.dichistoriasaude.coc.fiocruz.br <acesso 02/01/2017>

EDLER, Flávio; FONSECA, Maria Rachel Fróes da: Saber Erudito e Saber Popular na Medicina Colonial, Cadernos ABEM: 2 (2006), pp. 06-07.

ENGLERT, W. Ph.: Christus und Buddha in ihrem himmlischen Vorleben, Wien: Mayer, 1898.

FALKE, Robert: Zum Kampfe der drei Weltreligionen (Buddhismus, Islam, Christentum). Ein Katechismus für Wahrheitssuchende Leute, Gütersloh: Bertelsmann, 1902.

GIUMBELLI, Emerson: Heresia, doença, crime ou religião: o Espiritismo no discurso de médicos e cientistas sociais, Revista de Antropologia, 1997, v. 40, n 02 , pp. 31-82.

HAACK, Ernst: Christus oder Buddha? Schwerin: Fr. Bahn, 1898.

KARDEC, Allan: Livro dos Mediuns: Guia dos Médiuns e dos Evocadores, São Paulo: Petit, 2004.

KARDEC, Allan: O Evangelho segundo o Espiritismo, Brasília: Federação Espírita Brasileira, 2013.

KARDEC, Allan: Obras póstumas, São Paulo: Lake, 1995.

LINSE, Ulrich: Geisterseher und Wunderwirker. Heilssuche im Industriezeitalter, Frankfurt: Fischer, 1996.

MACHADO, Roberto et. al. Danação da norma: a medicina social e constituição da psiquiatria no Brasil, Rio de Janeiro: Ediçóes Graal, 1978.

MOREIRA, Nicolao Joaquim: Rápidas consideraçóes sobre o maravilhoso, $o$ charlatanismo e o exercício ilegal da medicina e da pharmácia, Rio de Janeiro, Typ. de M.Barreto, Mendes Campos \& Cia., 1862.

OLIVEIRA, A. X. de: Espiritismo e Loucura. Rio de Janeiro: A. Coelho Branco 1931.

PEUKERT, D.J.K.: Das Janusgesicht der Moderne, in: DIFF [org.]:

Jahrhundertwende. Die Entstehung der modernen Gesellschaft 1880-1930,

Weinheim/Basel, Beltz, 1988, pp. 60-106. 
RIBEIRO, Leonídio; CAMPOS, Murillo de: O Espiritismo no Brasil - contribuiçāo ao seu estudo clínico e médico-legal, São Paulo: Companhia Editora Nacional 1931.

RIBEIRO, Lourival: O Barão do Lavradio e a Higiene no Rio de Janeiro, Belo Horizonte; Rio de Janeiro: Editora Itatiaia, 1992.

SCHWARCZ, Lilia Moritz: O espetáculo das raças: cientistas, instituições e questão racial no Brasil, 1870-1930. São Paulo: Cia das Letras, 1993.

SIGOLO, Renata Palandri: Em busca da "Sciencia Medica": a medicina homeopática no início do século XX, Tese de doutorado em História, Curitiba, Universidade Federal do Paraná, 1999.

STOLL, Jaqueline: Espiritismo à Brasileira, Curitiba; São Paulo: Orion; Edusp, 2005.

Recebido: 01/08/2017

Aprovado: 31/09/2017 